\title{
Toward Inclusive Outreach: What Special Collections Can Learn from Disability Studies
}

\begin{abstract}
Recent statistics suggest that nearly 1 in 5 undergraduate students in the United States report having a disability. Educators and special collections practitioners are thus confronted with a difficult question: What can be done to ensure that these students receive the accessible educational experience they deserve - and that is legally mandated - within our institutions? This article seeks to begin a critical discourse relating to the design of inclusive outreach in special collections for persons with disabilities. We begin by briefly outlining the emergence of the Disability Rights Movement and its relationship to institutional libraries, highlighting in particular where we see opportunities for improving outreach to populations that have special access needs. Next, we offer strategies for building a program of user-centered, accessible outreach for special collections libraries, such as locating and partnering with key stakeholders, designing flexible instruction modules, and assessing outreach activities. Finally, we conclude with reflections on the value of accessibility to the mission of special collections. Ultimately, instituting a programmatic approach, such as that which we advocate here, aligns with the professional ethics of the field and improves the quality of the special collections experience for all of our many diverse patron groups.
\end{abstract}

According to the National Center for Education Statistics, 19 percent of undergraduates and nearly 12 percent of postbaccalaureate students in the United States during the 2015-2016 academic year reported having a disability. ${ }^{1}$ This is

1. National Center for Education Statistics, "Postsecondary Education," Digest of Education Statistics, 2017 (U.S. Department of Education, 2018), https://nces.ed.gov/programs/digest/d17/ch_3.asp. Debate persists in the disability studies community regarding the use of "People-First Language." This mode of rhetoric, which emerged in the early twenty-first century, argues that, when communicating about disability, the person should be privileged before the condition. Thus, a disability is something a person has, not something a person is (in other words, "individual with a disability" rather than "disabled individual"). Subsequently, many groups have come forward counterarguing that People-First Language undermines their identity as part of a given disability culture. For example, many people who have visual impairments choose to be identified as "blind people." For the purposes of this article, however, we choose to use People-First Language because it emphasizes and exemplifies the user-centered approach to accessibility that we advocate here. For more on this debate, see Roger Collier, "Person First Language: Noble Intent but to What Effect?” Canadian Medical Association Journal 204, no. 18 (2012): 1977-78; and Angelo Muredda, "Fixing Language: 'People-First' Language, Taxonomical Prescriptivism, and the Linguistic Location of Disability," The English Languages: History, Diaspora, Culture 3 (2012): 1-10.

(c) 2020 by Kevin M. O'Sullivan and Gia Alexander (CC BY-NC [https://creativecommons.org/ licenses/by-nc/4.0/]). 
a dramatic increase over data from the previous decade, which reported just 11 percent of undergraduates and 6 percent of postbaccalaureate students in the same category in 2003-2004. ${ }^{2}$ With these statistics in mind, educators and special collections practitioners are confronted with difficult questions: What are we doing to effectively meet the needs of nearly one in five of the undergraduates who sit in our classrooms? ? $^{3}$ What can we do to ensure they receive the accessible educational experience in our institutions that they deserve? While there has been a notable expansion in the critical conversation surrounding accessibility and inclusion since the emergence of disability studies in the late twentieth century, voices from the area of special collections have been largely silent. ${ }^{4}$ This article seeks to address this gap in the professional literature. We will begin by briefly outlining the emergence of the Disability Rights Movement and its relationship to institutional libraries, highlighting in particular where we see opportunities for improving outreach to populations that have special access needs. We will then offer strategies for building a program of accessible outreach for special collections libraries, such as locating and partnering with key stakeholders, designing flexible instruction modules, and assessing outreach activities. Finally, we will conclude with some thoughts on the value of accessibility to the mission of special collections. Ultimately, instituting a programmatic approach, such as the one we will advocate here, aligns with the professional ethics of the field and improves the quality of the special collections experience for all of our many diverse patron groups.

\section{Libraries and the Disability Rights Movement}

Before considering how special collections practitioners might best adapt their outreach strategies to accommodate a range of abilities, it is essential to first understand the rise of the Disability Rights Movement and its influence on our understanding of how disability is socially constructed. In the United States, public awareness of the rights of people with disabilities arose early in the twentieth century when the responsibility to meet their needs transferred from the family to the federal government. In response to the thousands of military personnel returning from World War I with significant and permanent injuries, new services for veterans and the resulting medical model of disability situated the problem of disability within the "broken

\footnotetext{
2. National Center for Education Statistics, "Students with Disabilities at Degree-Granting Postsecondary Institutions" (U.S. Department of Education, 2011), https://nces.ed.gov/pubsearch/pubsinfo. asp?pubid $=2011018$. Additionally, one must note that these are likely conservative numbers, as such statistics rely upon students self-identifying as disabled and electing to seek assistive services on campus.

3. Following the example set by the RBMS Task Force to Review the ACRL Code of Ethics for Special Collections Librarians, we have adopted "special collections practitioner" as a more inclusive terminology, which reflects the range of professional positions that may require primary source instruction.

4. A notable exception is work highlighting progress in making digital collections materials more accessible through the use of assistive technologies like screen readers. See, for example, Kristina L. Southwell and Jacquelyn Slater, "Accessibility of Digital Special Collections Using Screen Readers," Library Hi Tech 30, no. 3 (2012): 457-71.
} 
body" of the individual. ${ }^{5}$ This approach sought to rectify disability with often futile "cures" (for instance, lobotomy for mental illness) and to segregate individuals with disabilities in special care homes, hospitals, and asylums. ${ }^{6}$ As Gareth Williams noted, the medical model was "fundamentally positivist in its orientation to the world," prioritizing scientific data over the experience of the individual. ${ }^{7}$ Because of this narrow scientific focus, the medical model overlooked the impact of external factors that had the effect of disabling citizens. For example, prior to the ADA, there existed a widespread lack of ramps, curb cuts, or elevators that prevented those benefiting from a wheelchair from making full use of it. Nevertheless, the medical model remained the dominant framework for understanding disability until the advent of the Disability Rights Movement, which emerged in parallel to other social movements such as the Civil Rights Movement and the Women's Movement of the 1960s and 1970s.

In 1962, Ed Roberts made history by becoming the first student who required the use of a wheelchair to gain admission to the University of California, Berkeley. Throughout his academic career, Roberts challenged the medical model of disability as well as the academic and civic authorities around him. This activism progressed beyond the edges of his university campus, catalyzing early disability rights legislation for public colleges and universities around the country. Some 20 years before the ADA, Roberts's advocacy led directly to the establishment of Section 504 of the Rehabilitation Act of 1973, an early mandate for accessibility at public institutions of higher learning, and to the federal Rehabilitation Services Agency (RSA) in 1974. As a result of the far-reaching effects of his advocacy efforts, Roberts is regarded by many as the "father" of the Disability Rights Movement in the United States.

Another dramatic shift in how we think about disability arrived with the International Classification of Impairments, Disabilities, and Handicaps (ICIDH), which was published by the World Health Organization in 1980. With this document, the conception of disability progressed from an anatomico-pathological diagnosis to a "broader spectrum of personal and social needs [that] provided the basis for a much more realistic assessment of the prevalence for disability and an argument for increases and shifts in forms of provision." ${ }^{\text {In }}$ other words, following this social model, disability is construed not by some localized physiological condition, but the lived reality of a person as they navigate the institutional and societal relation-

5. See Colin Barnes, "The Social Model of Disability: A Sociological Phenomenon Ignored by Sociologists?” in The Disability Reader: Social Science Perspectives, ed. Tom Shakespeare (New York, NY: Continuum Books, 2005), 65-78.

6. See Simon Brisenden, "Independent Living and the Medical Model of Disability," Disability, Handicap \& Society 1, no. 2: 173-78.

7. Gareth Williams, "The Sociology of Disability: Towards a Materialist Phenomenology," in The Disability Reader: Social Science Perspectives, ed. Tom Shakespeare (New York, NY: Continuum Books, 2005), 236.

8. Williams, "The Sociology of Disability," 236. 
ships around them. In the social model, disability is not considered a condition that exists by virtue of one's abilities (or limits thereof). Rather, it is a construct that is imposed upon a person by the institutions around them that do not meet their basic needs.

Amid these broader shifts in thinking about the social construction of disability, progressive legislation continued to enact real change across the United States, particularly in the realm of education. Historically, access to an equal education was withheld from individuals with disabilities. And while progressive voices emerged across Europe and the United States at the turn of the twentieth century calling for integrated education for affected students, as late as the early 1970s, children who were born deaf or hard-of-hearing, or blind or with significant visual impairments, were segregated and educated at special state schools with other children having the same disability. ${ }^{9}$ As has been amply demonstrated throughout history, once ensured and protected, education may be the means by which marginalized groups are able to improve their station, gain independence, and live more fulfilling lives. Quickly following the Rehabilitation Act of 1973 came the Education for All Handicapped Children Act of 1975, which required all public schools that accepted federal funding to also provide equal access to education for students with disabilities. This legislation was amended and updated in 1990, when it was passed as the Individuals with Disabilities Education Act (IDEA).

The momentum of the Disability Rights Movement also led to the Americans with Disabilities Act of 1990 (amended 2009), which legally mandates accessibility to almost all public places, including libraries, and by extension their materials, including special collections. Public libraries, for example, provide accessibility to their physical locations via ramps, elevators, and specially constructed restrooms. But they must also make efforts to provide materials in alternative formats, such as Braille or audio. In the wake of this legislation, many libraries housed in historic buildings have struggled with accessibility issues, which often require costly renovations. ${ }^{10}$ Technically, some exceptions are permitted in the law regarding accessibility of historical sites. However, both patron engagement and public image stand to suffer for institutions that neglect to update their facilities. Fortunately, many special collections libraries have led with dramatic change. In 2019, for example, the Folger Shakespeare Library in Washington, DC, announced plans for a major building project. Among the stated purposes driving this effort is increased accessibility

9. Gerard Giordano, American Special Education: A History of Early Political Advocacy (New York, NY: Peter Lang Publishing, Inc., 2007), 39.

10. For more on this, see Library Buildings, Equipment and the ADA: Compliance Issues and Solutions, eds. Susan E. Cirillo and Robert E. Danford (Chicago, IL: ALA, 1996). 
to both facilities and materials. ${ }^{11}$ While the building is being made more usable, ongoing work to digitize the library's collections will mean that primary source materials can be more easily rendered in alternative formats, such as enlargement, audio, or Braille output, when requested. Although accessibility laws mark significant achievements, they are really just the beginning — a set of standards that must be met but that offer little guidance on how to achieve compliance. To best align with the ethics of our field, we would submit that special collections practitioners must extend these efforts beyond the minimum set by the legal mandate and strive for broader community engagement through a program of inclusive outreach.

Within the context of an academic library, many first forays into accessibility include making buildings and their contents more accessible and adjusting instructional practices to accommodate students with disabilities. ${ }^{12}$ However, we also have the opportunity to enact what Allison P. Hobgood describes as "radical institutional change," through which members of the academic community learn to preemptively account for physical and mental differences in their classrooms. ${ }^{13}$ If access to education is a human right, it follows that it is our ethical duty as information professionals to offer equal access to these opportunities to all members of our campus communities who wish to partake. We are left then with the difficult question of whether we are doing enough to account for the full spectrum of ability among our students and patrons.

In much the way that a social movement may begin with a single assertion of individual rights, the kind of radical institutional change Hobgood asks us to consider may begin with conversations among professionals in the field. We are fortunate to be in a time when such difficult dialogues related to matters of diversity are proceeding among those working in special collections. In 2018, the RBMS conference was devoted to the idea of "convergence." Among the stated ambitions of the program was to illuminate "our readiness for the inclusion of different people and cultures in what we collect, how we perform outreach and programming, and who we select to staff and lead our repositories." ${ }^{14}$ While many important and thought-provoking topics were introduced, close scrutiny of the conference program reveals no papers or panels speaking to services for persons with disabilities. Similarly, despite

11. Folger Shakespeare Library, "Building Renovation Project," https://www.folger.edu/about/ building-renovation-project [accessed February 20, 2020].

12. We would be remiss not to note the great strides that have been made to increase accessibility of collections materials through digitization. The scope of the present work, however, remains focused on outreach that incorporates physical special collections, specifically rare books, manuscripts, and other material artifacts.

13. Allison P. Hobgood, "An Introduction: On Caring," Pedagogy: Critical Approaches to Teaching Literature, Language, Composition, and Culture 15, no. 3 (October 2015): 414.

14. Rare Books and Manuscript Section, 2018 RBMS Conference program, http:// conference.rbms. info/2018/ [accessed February 20, 2020]. 
the explicit mention of encouraging participation of people of any physical ability and the desire to reach "the broadest possible population" in the RBMS Statement on Equity, Diversity, and Inclusion, the charge of the section's Diversity Committee makes no similar mention of patrons with disabilities. ${ }^{15}$ More recently, a task force was convened to review and amend the ACRL Code of Ethics for Special Collections Librarians. Included in the formal charge to the group was "expanding the scope of professional ethical duties therein described, and ensuring that the document empowers special collections professionals to incorporate ethical practice into their organizational and individual work." ${ }^{16}$ One of the core values highlighted in this revised document pertains to Collection Access and Accessibility: "Special collections practitioners demonstrate a proactive commitment to broad, equitable access to all materials under their stewardship, and constantly strive to improve collections access for all users." ${ }^{\prime 7}$ Significantly, the commentary supporting this core value explicitly calls for access policies that attend to the needs of patrons with disabilities. The area of Outreach, Reference, Instruction, and Exhibitions touches upon a similar motif, encouraging practitioners to "forge connections between collections and as diverse a community of users as possible, striving to find points of relevance that foster engagement at a multitude of levels." 18 The commentary here calls for equitable treatment of all patrons served by the collections.

The ongoing dialogue surrounding equality and diversity among practitioners and audiences of special collections is essential to the growth and sustainability of the field. While the updated Code of Ethics marks significant progress, it is clear that there remains a critical lack of awareness regarding the needs of persons with disabilities among special collections practitioners, particularly in the area of outreach and instruction. It is our hope that, by drawing attention to these issues in the pres-

\footnotetext{
15. Rare Books and Manuscripts Section, "Commitment to Equity, Diversity, and Inclusion," http:// rbms.info/about/\#diversity [accessed February 20, 2020]. The full statement reads: "The Rare Books and Manuscripts Section of ACRL/ALA is committed to equity, diversity, and inclusion in its membership, in rare books and special collections librarianship, and among users of rare books, manuscripts, and special collections. RBMS encourages participation in the section by people of any race, color, national origin, religion, gender, sexual orientation, age, and physical ability; it supports its members in serving the broadest possible population; and it seeks to represent the concerns and interests of rare books and special collections librarians at a variety of institutions, including academic libraries, public libraries, research libraries, special libraries, and historical societies." Rare Books and Manuscripts Section, "Diversity," http://rbms.info/diversity/ [accessed February 20, 2020]. The charge of the RBMS Diversity Committee is as follows: "To encourage members of underrepresented racial and ethnic groups to join and participate in RBMS; to recruit members of these groups into the Special Collections profession; to partner with other groups in the library field that focus on diversity or diverse collections; to generate and facilitate seminars, workshops, and programs about collecting materials related to racial and ethnic groups and providing outreach to patrons from diverse racial and ethnic backgrounds."

16. Rare Books and Manuscripts Section, "RBMS Task Force to Review the ACRL Code of Ethics for Special Collections Librarians," www.ala.org/acrl/rbms/acr-rbmtfce [accessed February 20, 2020].

17. As of this writing, a draft for the revised Code of Ethics has been approved by the RBMS Executive Committee and awaits formal approval from the ACRL Standards Committee. The draft approved by the RBMS Executive Committee may be read at https://t.co/1Gtus7hPwv?amp=1.

18. Ibid.
} 
ent argument, we can begin a vital, if difficult, dialogue that expands these ongoing efforts to improve diversity and together work toward extending services to all of our campus and community constituents. We will turn now to a consideration of steps that might be taken to make special collections outreach more accessible to persons with disabilities.

\section{Building a Program of Accessible Outreach in Special Collections}

Classroom instruction is an increasingly salient way for special collections institutions to demonstrate value to campus communities. ${ }^{19}$ A 2010 study analyzing forms of engagement by special collections practitioners conducted by the Association of Research Libraries revealed that 100 percent of respondents took part in curricular outreach, suggesting that this is now an essential function of our field. ${ }^{20}$ If we do our jobs well, the experience of special collections will be unlike anything else a student encounters during their education. Such instruction can play an integral role in the formation of what has been described as archival intelligence or artifactual literacy by building strong research skills in the location, use, and interpretation of primary source material. ${ }^{21}$ Beyond this, exposure to special collections can have a deep, personal effect on students with the potential to inspire lifelong learning. Magia G. Krause demonstrated that a hands-on, active learning approach forges powerful connections in a student's mind by inviting them to develop their own critical interpretation of the historical materials they handle. This experience offers "a sense of empowerment ... from seeing something new in the process of conducting original research." ${ }^{\prime 22}$ As more practitioners and faculty partner toward such active learning experiences in the special collections classroom, the importance of an unmediated, first-hand engagement with primary sources cannot be overstated. Classroom moments such as these are the result of creative thinking and careful planning. They require special collections practitioners to adopt a user-centered approach by critically evaluating the information-seeking behaviors of an audience before determining how best to reach them. ${ }^{23}$ It also requires an active and engaged

19. A 2006 survey conducted by the Association of Research Libraries (ARL) found that roughly 52 percent of survey respondents reported an increase in outreach activities. See Florence Turcotte and John Nemmers, Public Services in Special Collections, SPEC Kit 296 (Washington, DC: Association of Research Libraries, November 2006), 14.

20. Adam Berenbak et al., Special Collections Engagement, SPEC Kit 317 (Washington, DC: Association of Research Libraries, August 2010), 13. Respondents were special collections practitioners working on academic campuses.

21. Elizabeth Yakel and Deborah Torres, "AI: Archival Intelligence and User Expertise," American Archivist 66, no. 1 (Spring/Summer 2003): 52.

22. Magia G. Krause, “'It Makes History Alive for Them': The Role of Archivists and Special Collections Librarians in Instructing Undergraduates," Journal of Academic Librarianship 36, no. 5 (2010): 406.

23. Valerie Harris advocates for librarians and archivists "[putting] as much care and innovation into public services programs as they have in developing processes for description, access, and preservation," since many policies and procedures designed to protect collections materials may in fact pose barriers to our patrons' use of them. See Valerie A. Harris, "How Can I Help You? Becoming User-Centered in Special Collections," Archival Issues 32, no. 2 (2010): 71. 
dialogue with the course instructor(s) to define learning outcomes and the willingness to employ new strategies to most effectively achieve them. These same strategies may be readily applied toward the goal of developing more widely accessible instruction, ensuring that these formative special collections classroom moments are indeed available to the broadest possible population. Like any user-centered approach, such efforts must begin by understanding the needs of one's audience.

As we now understand it, both disability and disability identity exist as separate spectra, with each affected individual possessing their own unique experience of the world around them. For instance, vision impairment exists on a spectrum ranging from affected individuals who have no usable residual vision whatsoever to those who can read regular print with basic magnification. Besides these individuals, there are also those who experience difficulties that may not be formally recognized as disabilities, such as an older patron whose sight has diminished with age and who would benefit from the use of magnifying aids. Because of this wide range of access needs, a special collections practitioner may have three students with vision impairments in one class, each of whom requires a unique accessibility modification or accommodation, just as each experiences the classroom in their own way. Here we must make an important distinction between accessibility and accommodation. By accessibility, we mean applying forethought in designing inclusive experiences for library patrons. An accommodation (as in a Reasonable Accommodation mandated by the ADA) is a retrofit to our approach that we implement in response to perceiving a need or receiving a formal request. When providing an accommodation, the instructor must not presume the nuances of a condition, how it affects a student's work or experience of collections materials, nor what accommodations they will require. Furthermore, Anjali J. Forber-Pratt and Steven R. Aragon argue that the degree to which a person identifies as having a disability and their willingness to ask for and/or accept help also follow a spectrum. ${ }^{24}$ Some individuals deny disability altogether, while others regard their disability as intrinsic to their sense of self. One step in learning to live with a disability involves situating oneself somewhere along these spectra. Therefore, where a student is in this process - their level of comfort with disability, disclosure, and asking for help—may influence the type of support they need as well as how they request it. This means by extension that there are also students who would benefit from accommodations but are not yet in a position to request them. Entry into campus life may be the first opportunity some people with disabilities have to be among a large community of peers with the resources to support them. A better understanding of their needs and the accessibility affordances and accommodations available will continue to

24. Anjali J. Forber-Pratt and Steven R. Aragon, "A Model of Social and Psychosocial Identity Development for Postsecondary Students with Physical Disabilities," in Emerging Perspectives on Disability Studies, eds. Matthew Wappett and Katrina Arndt (New York, NY: Palgrave Macmillan, 2013), 16. 
evolve, as do their studies and participation in campus activities. ${ }^{25}$ Therefore, it is advisable to revisit conversations with individuals and inquire about whether there are any accommodations that would aid their success.

Here, some readers might argue that a universal design approach may be helpful to those individuals with disabilities who are uncomfortable asking for help, or unaware that they need it. Universal design began as a movement within the discipline of architecture to make buildings as accessible as possible to as many people as possible, regardless of their means of mobility (such as level entrances with no steps, automatic doors, and adequate elevators). The idea has since spread to other disciplines, including education, where instructors are tasked with designing learning activities that strive to be universally accessible. In an instructional video, for example, developers might take care to omit any features such as flashing lights that could potentially cause viewers to have seizures, add descriptive audio for users who have visual impairments, or add closed-captioning and transcription to accommodate users who have hearing disabilities. However, as Rick Godden and Jonathan Hsy pointed out, the notion of universal design comes with many "discontents," first among them being the idea that any design can be truly universal. ${ }^{26}$ As special collections practitioners, we are duty-bound to take steps to ensure our collections are available and usable to the broadest audience possible. Critics of universal design caution that the loftiness of such a goal may preempt an individual's ability to express their unique needs and thus preclude them from a more suitable, customized experience.

This critique of universal design again underscores the essential nature of communication among students, instructors, and special collections practitioners. Maintaining open channels of communication is essential to the success of designing a program of accessible outreach. On the individual scale, such feedback may arrive via an institution's ongoing assessment activities. ${ }^{27}$ However, one must attend to the privacy of the individual by arranging for such feedback to be related by some mechanism that does not force them to declare themselves as having a disability before their peers. Such feedback may begin as affective assessments (How did the individual respond to the instruction?) before proceeding to cognitive assessments (What did they learn?). As a program of accessible outreach gains a larger constituency, there may also be the opportunity for similar feedback on an institutional scale.

25. Forber-Pratt and Aragon, "A Model of Social and Psychosocial Identity Development for Postsecondary Students with Physical Disabilities," 17.

26. Rick Godden and Jonathan Hsy, "Universal Design and its Discontents," 2016 MLA Position Papers, Digital Edition, www.disruptingdh.com/universal-design-and-its-discontents/.

27. For more on assessment of special collections instruction, see Anne Bahde and Heather Smedberg, "Measuring the Magic: Assessment in the Special Collections and Archives Classroom," RBM 13, no. 2 (2012): 152-74. 
Valerie Harris and Ann C. Weller have argued that outreach activities provide special collections practitioners the opportunity to serve as "ambassadors for their institutions." ${ }^{28}$ There are obvious benefits to holding such a role on campus, such as greater visibility throughout the community, increased and more meaningful usage by patrons, and potentially gaining access to new opportunities for collections and external funding. ${ }^{29}$ Besides these, however, adopting such a role also opens the possibility for making new connections among underserved communities and upholding our professional ethics to provide equal access to education. Similar to a user-centered approach to instruction, the foundation for a successful ambassadorship is set by fostering new relationships built upon mutual respect and trust. This, in turn, relies upon open and continuous lines of communication in formal assessment surveys as well as informal feedback, which may then be analyzed and adopted.

Such an approach works particularly well for improving the experience of existing patrons of special collections. But how can one improve outreach for the previously underserved communities who are not yet among our user base? Valerie Harris suggested that, by listening to current patrons, we may promote a positive culture that then attracts new audiences. ${ }^{30}$ To reach the broadest possible population, however, we would recommend a more proactive approach be adopted to complement the one Harris suggests, one that offers such potential audiences the same opportunity for agency and feedback toward the improvement of special collections outreach. In the wake of landmark achievements like the ADA, and with the corresponding increase of awareness around disability issues in the public sphere, many campuses now have offices devoted to providing services for members of the campus community who have disabilities. Reaching out to colleagues in these units would be a logical first step toward learning more about the resources an institution offers for people with disabilities and thus begin a conversation about how the library may better serve them. To solicit such feedback, practitioners (and, ideally, administrators as well) might conduct a listening tour or host a town hall-style conversation for campus constituents. One might also consider forming an advisory committee comprising representatives from interested groups. This latter approach has the benefit of promoting an ongoing conversation and building in some level of accountability toward positive change. Underlying any approach is initiating communication with new stakeholders, offering them the opportunity to have a voice, and investing them in the work of special collections.

\footnotetext{
28. Valerie A. Harris and Ann C. Weller, "Use of Special Collections as an Opportunity for Outreach in the Academic Library," Journal of Library Administration 52, no. 3 / 4 (2012): 295.

29. Harris and Weller, "Use of Special Collections as an Opportunity for Outreach in the Academic Library,” 296.

30. Harris, "How Can I Help You?" 83.
} 


\section{Two Case Studies}

While the work of Ed Roberts and others led to greater community inclusion for many people with disabilities, controversy persists over how such involvement should be enacted. From the mid-1970s through the end of the twentieth century, well-meaning nonprofit entities, municipalities, and service providers sought to establish guidelines to manage the tide of people transitioning from institutions to communities. This led to a backlash against what was seen as prescriptiveness and undue limitation of personal freedoms for those with disabilities. As we have discussed previously, opponents of the broad, "one size fits all" approach advocated by universal design theorists cite its inability to accommodate or validate the needs, autonomy, and dignity of the individual. Thus, at the turn of the present century, the "Nothing About Us Without Us" movement took hold, calling for the involvement of people with disabilities in decisions regarding their care and experiences. ${ }^{31}$ With all of this in mind, it may seem counterproductive to offer prescriptive examples of what inclusive outreach is or ought to be. As opposed to providing templates for accessible instruction, it is our intention that the case studies below serve as models to demonstrate how this type of work operates in practice. We recognize that the inclusion of such personal accounts can prove useful in sparking ideas, building confidence, and further advocating for action. It is our hope that others will take up this mantle and contribute their own successes and failures in implementing programs of inclusive outreach to a growing body of critical work supporting this issue.

\section{Case Study 1: Incorporating a Bibliographical Teaching Collection}

Geoffrey Whitney wrote, in A Choice of Emblems, "Usus libri, non lectio prudentes facit"- It is the use of books, not simply the reading of them, that makes us wise. ${ }^{32}$ Thus, we are reminded that there is more to be achieved from sustained interaction with historical materials than the production of scholarly articles and monographs. Indeed, as special collections practitioners deepen relationships with a growing range of audiences, more ineffable benefits such as wonder, delight, and curiosity are recounted as qualitative indicators of meaningful impact. However, such experiences remain inaccessible to many who would benefit from and appreciate them. The professional best practices that guide how access is provided to researching patrons are vital to maintaining the security and preservation of our special collections material. By design, however, they also limit the varieties of outreach available for such valuable items. In the spirit of a user-centered approach, this case study demonstrates how a special collections practitioner might use a biblio-

31. For more on this social movement, see James I. Charlton, Nothing About Us Without Us: Disability Oppression and Empowerment (Berkeley, CA: University of California Press, 2000).

32. Geoffrey Whitney, A Choice of Emblems (Imprinted at Leiden in the house of Christopher Plantyn by Francis Raphelengius, 1586), 171. 
graphical teaching collection to offer innovative instruction that is adaptable to the specific needs of the audience.

A bibliographical teaching collection is made up of items that hold intrinsic artifactual value but do not possess significant monetary value, rarity, or scarcity and for which there is no commitment to long-term preservation. As a complement to the items we acquire and maintain within the secure stacks of our special collections libraries, such materials can serve as a powerful vehicle for introducing the world of rare books and manuscripts to diverse audiences outside the traditional boundaries of the reading room. ${ }^{33}$ Among the many benefits of adopting this approach are greater flexibility in outreach venues and the opportunity to reach a broader range of learning styles.

Since special collections materials are typically not permitted to leave the premises, a practitioner's audience must come to the library to receive hands-on instruction. Generally, this is seen as a good thing, as it brings students into special collections and introduces them to the resources available to them there. However, there are those in our community who are not able to travel to the library, whether due to a mobility issue or inaccessible facilities. For example, senior living communities often maintain a busy schedule of programs and events for the benefit of their residents. However, many who would enjoy engaging with the historical riches of special collections may be prevented from navigating to the library on a large college campus to take a tour. Through the use of a bibliographical teaching collection, it is possible to bring the experience of special collections to the audience, meeting them where they feel most safe and comfortable.

Such an approach also affords flexibility in the form of instruction. Each person possesses their own preferred learning style, which has been formed by a complex of biological and developmental factors over the course of their education. ${ }^{34} \mathrm{By}$ attending to such factors as instructional environment, the need for movement, or preferences around collaborative or individual learning experiences, an instructor can design an experience that is responsive to the needs of the audience. In particular, there are many for whom touch is an integral facet of the learning process. While one would not wish to promote the active destruction of a teaching resource, the materials composing a bibliographical teaching collection are not intended to be preserved in perpetuity, and thus there is less concern surrounding the manner in which they are handled. This opens up a wide range of possibilities for

33. For more on the development and use of such collections, see Kevin M. O'Sullivan, "The Continued Case for Bibliographical Teaching Collections," portal: Libraries and the Academy (forthcoming).

34. Rita Dunn, Jeffrey S. Beaudry, and Angela Klavas, "Survey of Research on Learning Styles," California Journal of Science Education 2, no. 2 (2002): 75, 87. 
tactile learners who require more sensation than is typically permissible in a special collections reading room. Moreover, the possibilities for tactile learning with a bibliographical teaching collection are further enhanced by the intrinsic nature of the materials that comprise it, which often come to the collection by virtue of their already being in moderate disrepair. Thus, with their sewing exposed or their plates detached, these items greatly reward a natural curiosity for physical materiality.

Highlighted in this brief case study are just two benefits of augmenting a special collections outreach program with a bibliographical teaching collection. However, as is generally the case in designing more accessible instruction, the beneficiaries of this approach are many more than persons with a disability. Having the flexibility to offer special collections-themed outreach outside the library will open new possibilities for events at K-12 schools, community centers, regional meetings, and promotional events around campus. And, with the ability to offer such hands-on interactions to more and different audiences, these outreach initiatives nevertheless instill wonder through a personal connection with historical materials.

\section{Case Study 2: Research-based Instructional Exercises}

Francesco Petrarch is often quoted as saying of his books:

I have friends, whose society is extremely agreeable to me: they are of all ages, and of every country. They have distinguished themselves both in the cabinet and in the field, and obtained high honors for their knowledge of the sciences. It is easy to gain access to them; for they are always at my service, and I admit them to my company, and dismiss them from it, whenever I please. ${ }^{35}$

But what if it is in fact not easy to gain access to books one needs for one's research? For many scholars with disabilities, meaningful access to valuable collections materials is possible only through the use of assistive devices, such as digital magnification technology. The same is true for students with disabilities, who come to special collections with the intention of honing the methodological skills that will serve them for the rest of their careers. This case study offers some reflections on how practitioners may design practice-based instructional exercises in the service of research methods training that are tailored to the specific needs of new scholars with disabilities.

As is the case for advanced scholars with disabilities who visit our reading rooms, open dialogue is the most effective tool for understanding the needs of individual students with disabilities. Under the law, it is the responsibility of the individual

35. Quoted in S. Austin Allibone, A Critical Dictionary of English Literature and British and American Authors (Philadelphia, PA: J.B. Lippincott, 1891), 14. 
with a disability to initiate that dialogue by self-disclosing their access needs and requesting specific accommodations. Typically, scholars with disabilities accomplish this task in their advance correspondence with training facilitators, a standard step in registering for such an event. If possible, scholars with disabilities often benefit from an advance visit to the facility, whether in person or by remote communication. In a preliminary meeting, a student with a disability will have the opportunity to bring and demonstrate any assistive technology they might anticipate using during the training event. In so doing, individualized procedures can be worked out in advance that meet the researcher's access needs while protecting the integrity of the materials. In some cases, accessibility enhancements may need to be made to allow specific assistive devices in the special collections facility. For example, many scholars with visual impairments use some form of digital magnification. Some of these devices use very bright light, which may be detrimental to artifacts. As an alternative, digital magnification technology is available that uses ambient rather than bright LED or fluorescent light. Advance knowledge of the need for digital magnification affords the individual or the institution time to procure the most optimal assistive technology.

Advance access to any tools or materials used in the group instructional exercise also benefits participants with disabilities. An advance copy of a course packet, for example, allows time for any needed alternative formats to be created. Similarly, taking the student through a "dry run" of activities increases both comfort and confidence for all parties concerned. For instance, familiarizing a participant who has impaired vision with a type-casting mould by allowing them to handle the object and become familiar with how the parts fit together saves awkwardness, embarrassment, and delays during the event itself. By taking this step, both the instructor and the student will know what to expect, and accessibility needs can be worked out in advance. These preparations save class time, but they also prevent the undue disclosure of a disability before the entire group.

Accessibility concerns related to such a group exercise do not end when the class is over. As we noted above, assessment through participant feedback is essential to improving the experiences we design for all of our library patrons. However, we often overlook the accessibility of the mechanism by which this feedback is gathered. Thus, we run the risk of silencing certain populations among our students. As a general rule, we would advise asking students how they would prefer to give their feedback at the conclusion of the instruction.

Communication and individualization are key to accommodating scholars with disabilities who need access to special collections, yet such improvements to accessibility can and do often have unforeseen benefits to all stakeholders. For example, 
the digital magnification tools noted above can be indispensable for detecting watermarks or identifying marks hidden deep within the gutter of a binding. Taking measures to make practice-based research exercises more accessible may thus benefit everyone.

\section{Benefits to All}

In the wake of the Americans with Disabilities Act, great strides have been made to improve the day-to-day lived experience of persons with disabilities. Crucially, this progress began with a recognition of institutional barriers, which (intentionally or not) had the effect of oppressing members of our society by placing limits on their personal freedoms. It is our hope that this article may serve a similar function by raising awareness of the lack of accessibility in special collections classrooms and thus begin a wider critical conversation toward broadly applicable improvements, such as adopting a user-centered approach in the design of accessible instruction and the formation of a student advisory board to guide the direction of meeting campus needs. A productive dialogue around strategies toward diversification and long-term sustainability continues to progress within the field of special collections. We would submit that it is crucial for any such dialogue to be as broadly inclusive as possible and that this must include voices from members of our communities who have disabilities.

The issues that we have raised are relevant beyond the traditional boundaries of disability and library studies. The practices encouraged here are broadly applicable and will lead to more meaningful classroom experiences for all of our students. The approach to outreach we advocate is a proactive one. It is self-consciously invested in reaching students where they are and is designed to meet their unique learning needs as individuals. If taken to heart, such strategies will also stimulate our creativity as educators, improving our teaching practice in any context. In so doing, we will more closely adhere to the ethics of our field, enhancing access to the cultural property in our care for the broadest possible population. 